\title{
Rationalisation of long-term high-dose opioids for chronic pain: Development of an intervention and conceptual framework
}

Bailey, John; Nafees, Sadia; Jones, Lucy; Poole, Rob

\section{British Journal of Pain}

DOI:

$10.1177 \% 2 F 2049463720958731$

Published: 01/08/2021

Peer reviewed version

Cyswllt i'r cyhoeddiad / Link to publication

Dyfyniad o'r fersiwn a gyhoeddwyd / Citation for published version (APA):

Bailey, J., Nafees, S., Jones, L., \& Poole, R. (2021). Rationalisation of long-term high-dose opioids for chronic pain: Development of an intervention and conceptual framework. British Journal of Pain, 15(3), 326-334. https://doi.org/10.1177\%2F2049463720958731

\footnotetext{
Hawliau Cyffredinol / General rights

Copyright and moral rights for the publications made accessible in the public portal are retained by the authors and/or other copyright owners and it is a condition of accessing publications that users recognise and abide by the legal requirements associated with these rights.

- Users may download and print one copy of any publication from the public portal for the purpose of private study or research.

- You may not further distribute the material or use it for any profit-making activity or commercial gain

- You may freely distribute the URL identifying the publication in the public portal?
}

Take down policy

If you believe that this document breaches copyright please contact us providing details, and we will remove access to the work immediately and investigate your claim. 


\section{Rationalisation of long-term high-dose opioids for chronic pain: Development of an intervention and conceptual framework}

Running head: Rationalisation of long-term high-dose opioids for chronic pain.

\section{Authors}

1. John Bailey*1, Research Officer j.bailey@bangor.ac.uk

Bangor University, Centre for Mental Health and Society, Wrexham Academic Unit, Wrexham Technology Park, Wrexham, LL13 7YP

ORCID: 0000-0001-9845-605X

2. Sadia Nafees ${ }^{1}$, Research Officer s.nafees@bangor.ac.uk

3. Lucy Jones ${ }^{2}$, Clinical Nurse Specialist (LUCY.JONES4@wales.nhs.uk)

4. Rob Poole ${ }^{1,2}$, Hon. Consultant Psychiatrist (ROB.POOLE@wales.nhs.uk)

${ }^{1}$ Centre for Mental Health and Society.

${ }^{2}$ Betsi Cadwaladr University Health Board.

* = corresponding author

\section{Declarations}

Conflicting interests: The Authors declare that there is no conflict of interest.

Funding: This research received no specific grant from any funding agency in the public, commercial, or not-for-profit sectors.

Informed consent: For the qualitative study data reported, written informed consent was obtained from all participants before the study began.

Ethical approval: No ethical approval was sought for the description of the development of the intervention and its procedure; it refers to routine clinical activity involving the prescription of drugs for their licensed indication. NHS ethical approval was not required for the reported routinely collected data; permissions from the local Clinical Audit and Effectiveness Department were obtained and ethical approval was given by Bangor University School of Health Sciences Ethics Committee. For the qualitative study data reported, the research was approved by the Research Ethics Service, Wales Research Ethics Committee 5 (18/WA/0065) and by Bangor University School of Health Sciences Ethics Committee (2018-16258).

Guarantor: JB.

Contributorship: JB and SN conceived and developed the paper. $\amalg$ and RP developed the intervention. $\sqcup, \mathrm{RP}$ and JB developed the associated conceptual framework. JB researched the 
literature, collated the outcome data, collected and analysed the interview data and wrote the first draft of the manuscript. All authors reviewed and edited the manuscript and approved the final version of the manuscript.

Acknowledgements: We are grateful for the help provided by Amanda David in collecting the outcome information included in this study. 


\section{Abstract}

There has been a large increase in the number of prescriptions for opioid drugs in the UK over the last twenty years or more and the prescribing of opioids in high doses continues to increase. Much opioid prescribing is for chronic non-cancer pain (CNCP) despite serious doubts about the long-term effectiveness of opioids for this indication. Clinical experience is that there are increasing numbers of patients who are on high dosages of opioid drugs over sustained periods which provide limited or no pain relief whilst having significant negative effects on functioning and quality of life. The aim of this paper is to bring readers' attention to some clinical observations of the CNCP population with high doses and to describe an intervention to reduce these doses. Many of these patients have no clinical features of addiction; we suggest that those who show little or no substance misuse behaviours are best understood as a distinct clinical population who have different treatment needs. In order to understand and treat these patients, a model is required which, rather than seeing the problem as lying solely with the patient, focuses on the interaction between the individual and his or her environment and seeks a change in what the patient does every day, rather than a simple, and largely unattainable, goal of symptom elimination. The clinician authors worked together to develop an intervention based upon approaches taken from both pain management and psychiatric practice. A detailed description of this rapid opioid reduction intervention (RORI) is provided along with some preliminary outcome data.

Keywords: opioids; methadone; chronic pain; pain management; drug reduction; psychosocial intervention 


\section{Background and Rationale}

There has been a large increase in the number of prescriptions for opioid drugs in the UK over the last twenty years or more [1-5]. Recent research suggests that this pattern has not reversed $[6,7]$. There is evidence of continuing increases in the use of strong opioids and high doses [8,9]. There have been similar increases throughout the developed world [10], with the largest increases in North America [11-13]. Most of this prescribing is for chronic non-cancer pain (CNCP) $[2,4,8]$ despite serious doubts about the long-term effectiveness of opioids for this indication [14-18]. There is evidence of direct and indirect harms resulting from such use of opioids [15,19-24].

There are problems with other drugs used in the treatment of CNCP, but the lethal potential of opioids causes particular concern. In the UK, there has been a focus on avoiding the severe problems encountered in the USA [25-28].

\section{Distinct population}

Concomitant to the increase in prescriptions, a significant minority of chronic pain patients across the NHS take high doses of opioids for long periods. For many patients, these high doses provide little or no additional pain relief over more modest dose regimens, whilst producing significant negative effects on functioning and quality of life [29]. We have labelled this phenomenon Dysfunctional Therapeutic Opioid Use (DTOU).

There is a temptation to see all of the problems encountered by long-term users of opioids for CNCP in terms of substance misuse and to suggest that they can be dealt with through substance misuse treatment approaches. There are similarities between substance misuse and DTOU patients in the effects of the drugs they use and some DTOU patients show some clinical features of addiction, such as lying to family about their drug use or hoarding medications. However, many DTOU patients have no clinical features of substance misuse. Where clinical features of addiction predominate, referral to substance misuse services is appropriate. We suggest that those who show no (or only minor) substance misuse behaviours are best understood as a distinct clinical population who have different treatment needs.

This is not to deny that some people with a primary addiction problem obtain drugs through pain prescriptions or that opioid use for CNCP sometimes leads on to addiction. Instead, we suggest that the conceptualisation of the problems of DTOU patients as necessarily a form of substance misuse is misleading and unhelpful. A substance misuse model assumes motivations for use other than chronic pain, and consequently cannot be used to address the specific problems of DTOU patients. Treatments for substance misuse and for chronic pain have different objectives. For substance misuse they are drug substitution, harm reduction and, ultimately, abstinence; for chronic pain they are optimising pain relief and personal functioning, balancing drug benefits and adverse effects. What they have in common is a need for harm reduction.

In North America, considerable research attention has been paid to substance misusers and pain management services (see, for example, [30-38]). This has two main aims. The first of these is to identify patients who have an established substance use disorder, in order to 
prevent abuse of the services. The second is to identify factors predicting the development of substance misuse amongst those who are prescribed opioid medication. Whilst the approach is logical, it has not proven fruitful; systematic reviews suggest that it has not led to the development of reliable instruments with adequate specificity and sensitivity $[15,39$, 40 and see 41,42$]$.

We agree with the formulation of Schofferman [43] who describes an upward spiral of opioid use whilst the patient's functioning spirals downward. He says

...patients may become less functional. They may become depressed, anxious, or irritable. They often have disturbed sleep. Patients usually attribute the problems to the continued pain, not to the opioids. Their life may become more centered around appointments with doctors, often to renew medications. These patients are not malingering, exaggerating, or abusing their drugs. They are seeking pain relief. [p 286; emphasis added].

\section{Clinical observations}

On first assessment, many patients referred to UK secondary care pain management services have often been prescribed high doses of opioid medication for some time: and yet the usual reason for referral is inadequate pain relief. Most are also prescribed adjuvant medications, many of which are sedative, have dependency-forming potential, and exacerbate opioid adverse effects.

In primary care, indirect (aggregated prescribing data) and anecdotal evidence suggest that a significant number of patients who are not known to pain management services are prescribed high doses of opioids for CNCP. There are few studies of these patients. It is reasonable to suppose that a proportion of them have, or will develop, DTOU.

It is not clear how high-dose and high potency regimens originate. Whilst for some patients, high doses appear to develop in primary care, other patients are discharged from hospital on high potency opioids without clear plans for using or stopping these medications. In addition, some pain management clinicians advocate high-dose and high potency regimens.

There are some common features evident from treating such patients in secondary care pain services.

\section{Resistance to dose reduction}

Patients often experience some pain relief at the beginning of treatment with opioids, but this does not persist. This means that the goal of successful pain relief through medication can appear attainable to them.

These patients go through an escalating cycle of pain and drug doses where initial pain reduction is followed by a return to previous pain levels, addressed by increased doses. This is successful in the short term but is followed by returning pain, and so on. This attenuation of pain relief is often interpreted by many patients and their doctors as evidence of worsening of their painful condition. However, in a proportion of cases, it is likely to be due to opioid-induced hyperalgesia (that is, pain that diminishes in intensity when opioid medication is reduced or discontinued), a recognised effect of continuous use of opioids, particularly in high doses $[20,21,44]$. Some analyses of the mechanisms for hyperalgesia 
suggest that it is closely linked to tolerance $[45,46]$ and that, like tolerance, it may be a universal property of opioids [46].

In our experience, people who have endured severe chronic pain are fearful of its return. Warnings about the dangers of high doses of opioids often confirm their belief that their pain is exceptionally severe and deteriorating, and that they will be overwhelmed by pain if the drugs are reduced or discontinued.

\section{Lack of evidence on reduction of high doses of opioid}

There is a lack of reliable research evidence for the prescription and use of opioid medication for CNCP $[15,17,47,48]$; a recent Cochrane review failed to find high quality evidence on the use of high doses of opioids for CNCP [18]. There is also a paucity of evidence-based interventions for the reduction of high doses of opioids [49,50]; expert guidelines recommend the staged reduction or tapering of prescribed opioid doses where necessary [51-55] but there appear to be few studies evaluating the effectiveness of this procedure in pain patients. Two recent reports of trials of tapering with patients with prolonged high doses of prescribed opioids raise questions about the likely effectiveness of this procedure with this patient group $[56,57]$. Both studies encountered serious difficulties with the recruitment and retention of participants and in achieving compliance with the study procedures. This resulted in a failure to complete the planned interventions. Other researchers have questioned the effectiveness of tapering with users of high-dose opioids and suggested that, in some patients, it results in deteriorating health [58]. Our clinical experience is that patients find slow tapering difficult due to the repeated initial increase in pain following dose reductions and the lack of immediate and marked benefits.

\section{Model of care in pain management}

Substance misuse services and pain specialists both treat some patients with chronic pain and drug related problems and both groups use models which primarily locate problems in the patient. Pain physicians routinely look for physiological sources of pain which can be addressed through physical intervention or through drugs. Difficulties, and conflicts with patients, arise when physiological sources cannot be identified or effective interventions cannot be devised. Substance misuse models also focus on patient vulnerabilities (physiological, genetic, psychological or social) which lead to addiction problems on exposure to substances.

We suggest that, in order to understand and treat DTOU, a model is required which, rather than seeing the problem as lying solely with the patient, sees it as a trap into which patients and prescribers can fall, in which the prescriber, the health system and patient factors all play an active role. A model is needed which focuses on the interaction between the individual and his or her environment and seeks a change in what the patient does every day, rather than a simple, and largely unattainable, goal of symptom elimination. 


\section{Intervention}

\section{Process of an intervention development}

An experienced liaison psychiatrist (RP) with an interest in substance misuse offered one session/week with a hospital based pain management team, mainly assessing inpatients on high-dose opioids. In some cases, methadone substitution was commenced during the admission. Following national prescribing guidelines [59], the starting dose was methadone $20 \mathrm{mg} /$ day. Few patients needed an increase in methadone dose to control pain or withdrawal symptoms, and the patients did not report drug craving. Some patients needed follow up, and a specialist clinic was set up. Over time, working within the pain management team, outpatients were referred for intervention. The regimen set out below was developed for these outpatients by the same psychiatrist and an experienced clinical nurse specialist in pain management with the aim of reducing from high doses of standard opioids to low dose methadone, which is distinct from methadone substitution in harm reduction management of opiate addiction. Intervention development relied upon first principles of rational prescribing [60] and trial-and-error to find strategies that might help to reduce medication adverse effects and improve patients' quality of life without a worsening of pain. Low dose methadone was just one treatment option that was offered to appropriate patients.

The intervention that has been developed relies upon four conceptual elements:

1. The patient. A clear understanding of each patient's circumstances and experiences of pain and medication, along with an exploration of their meanings and the expectations which patients have for treatment. The involvement of family members or carers is important; they help in understanding the patient's circumstances and are often influential in changing or maintaining the patient's medication use.

2. The prescriber. In every case, a prescriber initiates these regimens and has increased dosage in good faith, despite a lack of persistent pain relief, impairment of social functioning and poor quality of life. Understanding the prescriber's dilemma, and providing them with responses other than drug treatment is essential if change is to be sustained.

3. The drugs. A sophisticated understanding of both pain and the drugs used to treat it are crucial. In some areas there is a serious lack of evidence, particularly with regard to hyperalgesia and effects on mood and cognitive functioning.

4. Health care systems. It is necessary to pay attention to the new ways that an overstretched healthcare system functions, often with unintended consequences such as atomisation of care and the loss of clear locus of control of treatment.

Administrative actions, such as formulary changes designed to reduce prescribing of drugs of particular concern (e.g. tramadol), can focus prescriber attention on 'which drug?' rather than encouraging a broader framework of pain management. It is also necessary to consider wider social factors, including the impact of the attitudes, expectations and assumptions of patients and prescribers about pain and about healthcare and its delivery. 


\section{The developed intervention}

The rapid opioid reduction intervention (RORI) is offered to patients who have been assessed by the secondary care pain management service. The purpose is to optimise medication use and promote non-pharmacological pain management strategies. Patients are accepted who are on long-term (12 months or more) high dose opioid medication regimens (using the generally accepted criterion of $\geq 120 \mathrm{mg} /$ day oral morphine equivalent $\{M E\}$ dose [29]) with poor pain relief and where the pain management multidisciplinary team consider medication reduction is necessary. This may arise before or after other pain interventions, or where other treatment options have been exhausted.

RORI depends upon joint working by a pain nurse specialist and a consultant psychiatrist who are able to deliver a fundamentally psychosocial intervention, whilst attending to biomedical aspects of the patients problem. We understand our patients and their doctors as being caught in a trap which can only be escaped by a complete change of strategy by all concerned. Accordingly, the intervention draws the principles of Milan School systemic family therapy (direct involvement of family members, neutrality, circularity, hypothesising, positive connotation, paradoxical intention) $[61,62]$ as well as more commonplace elements of pain management such as careful history taking, attention to the origins, development and effects of their painful condition(s), and the use and consequences of all drugs taken to alleviate pain. Table 1 sets out the main psycho-social elements of the intervention. At the time of writing, the intervention is not manualised.

\section{Table 1 about here}

There is a careful explanation of the rationale for radically reducing opioids and adjunctive medications (benzodiazepines, other hypnotics and anxiolytics, antidepressants, GABA drugs). When necessary, before the opioid intervention, there is rationalisation or reduction of adjuvant medication, using standard dose tapering strategies, taking into account the drug, the dose and the patient's needs.

In RORI, the outcome offered is that pain will be no worse but that the patient's overall condition will improve. Patients are offered informed choices between no change, graded reduction or rapid reduction of their opioid drug regimens. We recommend the latter strategy, as it appears to be the most effective, particularly where high dose opioids are replaced by very much lower doses of methadone (typically methadone tablets $10 \mathrm{mg}$ twice a day). In all approaches, the prescription of additional ('PRN') doses for when pain is particularly severe is strongly discouraged and with methadone it is forbidden. In our preferred regimen, the changeover is conducted on an outpatient basis over SundayMonday night. Loperamide is used to control gastrointestinal withdrawal symptoms. There is a pre-arranged telephone contact after 36 hours and a face-to-face joint review on day 4. This is repeated the following week. Patients, relatives and their GP are given a number to contact within working hours for advice. GPs and patients are advised that until discharge from follow up, all decisions regarding pain medication should be made by the specialist 
team. This warning is placed on primary care records, along with the information that the patient is receiving methadone for treatment of pain rather than addiction. The patient is given a card to carry with this information and contact numbers. Recognising that specialist support is only available within office hours, all warnings and doctor/patient information also carry the advice that, in the event of an intervening medical emergency requiring strong analgesia, methadone should be discontinued and the patient should be managed as if opioid naïve (that is, ignoring any earlier opioid tolerance).

Patients are offered follow-up support for as long as they wish post-intervention, with the option of returning to their previous approach (but not previous doses) if they wish. Further non-drug interventions, focusing on learning to manage rather than eliminate pain, are offered (see Table 2). Supplementary documents are provided for procedural description of the intervention including information leaflet for GPs (Sup 1), and RORI procedure (Sup 2).

The intended patient outcomes of RORI are: improved day-to-day functioning; improved mood; improved cognitive functioning; improved patient safety (for example through reduction of risk of accidental overdose); improved sense of personal agency; improved ability to engage with non-pharmacological pain management. These outcomes are often not satisfactorily captured through standardised outcome measures. We will separately report a qualatitive study examining patients experience before and after opioid dose reduction. Outcome measures that we have trialed include: Brief Pain Inventory [63] pain location and current pain level measures; Hospital Anxiety and Depression Scale [64]; a specially constructed measure of Participation in Social Roles and Activities using validated items from PROMIS [65]; and pulse oximetry. So far, insufficient data has been collected to provide satisfactory measures of outcome, but this is work in progress.

The intervention is associated with a substantial programme of related research about various aspects of patient experience, the effects of high dose opioids on individual patients and prescribing patterns in primary care. Findings from this programme of research will be submitted for publication shortly.

\section{Table 2 about here}

\section{Evaluation ${ }^{1}$}

During 2014, patients were seen from time-to-time in an existing nursed-led pain management clinic. In 2015 a separate formal monthly joint clinic (LJ and RP) was set up and in July 2017 this became a weekly clinic. A small number of patients were seen where the primary medication of concern was not an opioid or opioid doses were below the level at which RORI would usually be offered. All patients had previously been fully assessed by the pain management team. Data was routinely collected to monitor and evaluate the clinic.

\footnotetext{
${ }^{1}$ For the reporting of routinely collected data, permission was obtained from the local Clinical Audit and Effectiveness Department and ethical approval was given by Bangor University School of Health Sciences Ethics Committee. For the qualitative study data reported, the research was approved by the Research Ethics Service, Wales Research Ethics Committee 5 (18/WA/0065) and by Bangor University School of Health Sciences Ethics Committee (2018-16258); all participants gave informed consent at the start of this study.
} 
Between 2014 and February 2020, 87 patients were assessed in the clinic. 41 (47\%) of the patients were female; the median age at referral was 51, range 25-77, IQR 43-58.

$28 / 87$ (32\%) did not engage, in that they either failed to attend their first or second appointment and did not accept invitations to be seen again. The proportion of referred patients who do not engage decreased over time.

$20 / 87$ patients (23\%) chose rapid change to low dose methadone. Their mean daily opioid dose at referral was $357 \mathrm{mgME}^{2}$, range $80-800 \mathrm{mgME}$. Four (20\%) methadone patients switched back to other opioids. One patient requested this because of inadequate pain relief and in another case methadone was stopped on safety grounds after a concurrent opioid was commenced by a different team. Neither of these patients returned to their previous level of ME doses in the next 12 months. Two other patients had methadone discontinued for medical reasons. There were no critical incidents amongst any of the 20 methadone patients, and none has died.

20/87 are currently active clinic patients and have not undergone the rapid dose-reduction intervention. Their mean daily opioid dose at referral was $233 \mathrm{mgME}$, range $38-720 \mathrm{mgME}$. A number of these patients have been assessed as unsuitable for methadone (for example, because of medical contraindications, chaotic life circumstances or history of taking opioids above prescribed doses) or have doses below the usual intervention threshold; some have undergone alternative medication rationalisation interventions. Eleven patients remain as future candidates for the intervention.

The remaining 19 patients either accepted more gradual reduction; or decided against dose reduction of opioids; or reduced other drugs. They were discharged by agreement with the patient to GP care once active intervention and regimen changes were complete. A few patients were discharged back to the care of the main pain management team where a specific intervention was indicated.

As part of a separate, ongoing qualitative study of patients' and family members' experiences of chronic pain and the use of long-term high-dose opioids, interviews were conducted with ten patients after the change to low-dose methadone. Nine out of ten reported that prior to the change, increasing doses of opioids had not eased their pain. Nine out of ten reported an improved or much improved mood after the change. All reported increased alertness. Seven out of ten reported improvement in pain; two reported no change in pain; one reported some deterioration in pain (but the latter patient reports positive outcomes overall.) Six out of ten reported increased levels of activity; several of these patients have activity-restricting underlying medical conditions. These self-reports were confirmed in the seven cases where partners were interviewed. All of the patients and their partners emphatically rejected the idea of a return to their previous drug regime.

\footnotetext{
2 Morphine equivalent doses were calculated using ratios published by the Royal College of Anaesthetists Faculty of Pain Medicine [66]
} 


\section{Discussion}

In summary, there is currently much concern about over-prescription of the opioid medication for CNCP, particularly the higher potency drugs and higher doses. Nevertheless, there is little evidence on how people on long-term high dose medication regimens can be helped to optimal pain management. We suggest that this requires a broader understanding of pain and its treatment. We also suggest that the problem is not mainly due to bad prescribers or drug-misusing patients. However, prescribers must recognise the potential adverse consequences of a commonly utilised treatment. It is incumbent upon individual clinicians and managers of health services to take responsibility for limiting them.

We have developed an intervention that appears to help a proportion of patients on highdose long-term opioids whose problems previously appeared intractable. However, whilst the audit data presented here is promising, our data must be interpreted with great caution. No firm claims of effectiveness can be made without a proper clinical trial.

\section{Conclusion}

This paper describes an intervention for DTOU and sets out the conceptual framework that was helpful in developing it. Although our experience suggests that the approach is effective and safe, including treatment with low dose methadone, we cannot yet provide high quality evidence to support this assertion. We offer it here as a contribution to the conceptual development of new responses to intractable pain and 'the opioid crisis'. Our clinic is the focus of research activity, and we will be reporting findings from a longitudinal community prevalence study and a qualitative study of patient and carer experience in the near future. The clinic is audited and we are seeking funding to more comprehensively evaluate the intervention. 
Table 1: Main psychosocial elements of the intervention

- Engagement \& rapport.

- Involvement of family or partner wherever possible.

- Preparedness to listen; history-taking focuses on the story that the patient and family want to tell. Where applicable, to accept the sense of grievance or betrayal by specific practitioners or the health system in general; to acknowledge feelings of powerlessness, hopelessness and abandonment.

- Acknowledgement of the validity of their perspective.

- Avoidance of explicit or implicit patient blaming (e.g. avoiding medication "contracts") or doctor blaming (positive connotation of motivations for past decisions).

- Acknowledgement of pain and of compliance with past medical advice.

- Exploration of health beliefs. Acknowledgement of limitations to medical tests and understanding.

- Agreement of new treatment aims.

- Explanation of chronic pain and its relationship to tissue damage.

- Provision of verbal, written and digital information.

- Setting of limited goals (i.e. to feel better with pain no worse).

- Prediction of fluctuations in pain irrespective of medication regimen.

- Rationalisation of medication and radical reduction of opioids.

- All medication changes made with patient agreement (as consent is not essential for medication discontinuation).

- Permanent option for patiernt to return to previous drug regimen.

- Mandatory cooling-off period or thinking time for decision to start dose reduction.

- Frank acknowledgement that rapid transition to low-dose opioids will involve unpleasant (but not dangerous) short-lived withdrawal effects.

- Provision of intensive support during transition.

- Post medication change work.

- Reassurance that follow up will continue until regimen is stable, and that discharge will only occur by prior agreement.

- Exploit functional improvement through problem-solving approach to achieve self-determined targets.

- Overcome demoralisation, low expectations and restricted life objectives and restore hope.

- Complete discontinuation of analgesia (and adjuvant medications) where patient wants this by tapering residual medication.

- Option of self-referral post-discharge. 


\section{Table 2: Non-pharmacological pain strategies}

- Time and timing: offer patients non-pharmacological interventions when they are ready, rather than at the outset when they are still focused on a pharmacological solutions.

- Set expexctations and specific treatment goals for each intervention.

- Provision of information e.g. on posture, firm upholstery, and low back pain and sofas. This often has to be repeated several times.

- Advice on distraction, relaxation and use of heat packs or TENS machines.

- Acupuncture.

- Physiotherapy assessment and intervention.

- Clinical psychology intervention where there is a clear goal for this.

- Concurrent involvement in a short Educational Patient Programme or a comprehensive Pain Management Programme.

- Where waiting times are excessive or patient preference is for one-to-one work, Pain Management Programme can be delivered through a workbook.

- Recommendation to use voluntary sector resources such as chronic pain support group or counselling services. 
Rationalisation of long-term high-dose opioids for chronic pain

\section{References}

1. National Treatment Agency for Substance Misuse (NTA). Addiction to Medicine. http://webarchive.nationalarchives.gov.uk/20120502165324/http://www.nta.nhs.uk/uploads/a ddictiontomedicinesmay2011a.pdf (2011, accessed 12 August 2019)

2. Health and Social Care Information Centre Prescriptions dispensed in the community: England 2002-2012. https://files.digital.nhs.uk/publicationimport/pub11xxx/pub11291/pres-disp-comeng-2002-12-rep.pdf (2013, accessed 12 August 2019)

3. Ruscitto A, Smith BH and Guthrie, B. Changes in opioid and other analgesic use 1995-2010: Repeated cross-sectional analysis of dispensed prescribing for a large geographical population in Scotland. European Journal of Pain 2015; 19: 59-66.

4. Zin CS, Chen L-C and Knaggs R. Changes in trends and pattern of strong opioid prescribing in primary care. European Journal of Pain 2014; 18; 1343-1351.

5. Foy R, Leaman B, McCrorie C et al. Prescribed opioids in primary care: cross-sectional and longitudinal analyses of influence of patient and practice characteristics. BMJ Open 2016; 6: e010276.

6. Cartagena Farias J, Porter L, McManus S et al. Prescribing patterns in dependence forming medicines. 2017; London: NatCen.

7. Mordecai L, Reynolds C, Donaldson Let al. Patterns of regional variation of opioid prescribing in primary care in England: a retrospective observational study. British Journal of General Practice 2018; 68: e225-e233.

8. Davies E, Phillips C, Rance J etal. Examining patterns in opioid prescribing for non-cancer-related pain in Wales: preliminary data from a retrospective cross-sectional study using large datasets. British Journal of Pain 2019; 13:145-158.

9. Curtis $\mathrm{HJ}$, Croker R, Walker AJ et al. Opioid prescribing trends and geographical variation in England, 1998-2018: a retrospective database study. Lancet Psychiatry 2019; 6: 140-150.

10. Berterame S, Erthal J, Thomas J et al. Use of and barriers to access to opioid analgesics: a worldwide, regional, and national study. Lancet 2016; 387: 1644-1656.

11. Fischer $B$, Jones $W$, Vojtila L et al. Patterns, changes, and trends in prescription opioid dispensing in Canada, 2005-2016. Pain Physician 2018; 21: 219-228.

12. Okie S. A Flood of Opioids, a Rising Tide of Deaths. N Eng/ J Med 2010; 363: 1981-1985.

13. Manchikanti L, Helm S, Fellows B et al. Opioid epidemic in the United States. Pain Physician 2012; 15: ES9-ES38.

14. Noble M, Treadwell JR, TregearSJ et al. Long-term opioid management for chronic noncancer pain. Cochrane Database of Systematic Reviews 2010; Issue 11. 
Rationalisation of long-term high-dose opioids for chronic pain

15. Manchikanti L, Vallejo R, Manchikanti KN et al Effectiveness of long-term opioid therapy for chronic non-cancer pain. Pain Physician 2011; 14: E133-E156.

16. Chan BKB, Tam LK, Wat CY et al. Opioids in chronic non-cancer pain. Expert Opinion on Pharmacotherapy 2011; 12: 705-720.

17. Chou R, Turner JA, Devine EB et al. The effectiveness and risks of long-term opioid therapy for chronic pain: a systematic review for a National Institutes of Health Pathways to Prevention Workshop. Annals of InternalMedicine 2015; 162: 276-286.

18. Els $C$, Jackson TD, Hagtvedt R et al. High-dose opioids for chronic non-cancer pain: an overview of Cochrane Reviews. Cochrane Database of Systematic Reviews 2017; Issue 10. Art. No.: CD012299.

19. Sjogren $P, G$ ronbaek M, Peuckmann V et al. A population-based cohort study on chronic pain: the role of opioids. Clinical Journal of Pain 2010; 26: 763-769.

20. Lee $\mathrm{M}$, Silverman $\mathrm{SM}$, Hansen $\mathrm{H}$ et al. A comprehensive review of opioid-induced hyperalgesia. Pain Physician 2011; 14: 145-161.

21. Brush DE. Complications of long-term opioid therapy for management of chronic pain: the paradox of opioid-induced hyperalgesia. Journal of MedicalToxicology 2012; 8: 387-392.

22. Labianca R, Sarzi-Puttini P, Zuccaro SM et al. Adverse effects associated with non-opioid and opioid treatment in patients with chronic pain. Clinical Drug Investigation 2012 32(Sup 1): 53-63.

23. Els C, Jackson TD, Kunyk D eta al. Adverse events associated with medium- and long-term use of opioids for chronic non-cancer pain: an overview of Cochrane Reviews. Cochrane Database of Systematic Reviews 2017; Issue 10. Art. No.: CD012509.

24. Vowles KE, McEntee ML, Julnes PS et al. Rates of opioid misuse, abuse, and addiction in chronic pain: a systematic review and data synthesis. Pain 2015; 156: 569-576.

25. Dhalla IA, Persaud N, Juurlink DN. Facing up to the prescription opioid crisis. BMJ 2011; 343: d5142.

26. Stannard C. Opioids in the UK: what's the problem? BMJ 2013; 347: f5108.

27. Kotecha MK and Sites BD. Pain policy and abuse of prescription opioids in the USA: a cautionary tale for Europe. Anaesthesia 2013; 68: 1210-1215.

28. Weisberg DF, Becker WC, Fiellin DA et al. Prescription opioid misuse in the United States and the United Kingdom: Cautionary lessons. International Journal of Drug Policy 2014; 25: 1124-1130.

29. RCoA, Faculty of Pain Medicine. Opioids Aware. https://fpm.ac.uk/opioids-aware (2020, accessed 28 February 2020).

30. Dowling LS, Gatchel RJ, Adams LL et al. An evaluation of the predictive validity of the Pain Medication Questionnaire with a heterogeneous group of patients with chronic pain. Journal of Opioid Management 2007; 3: 257-266. 
Rationalisation of long-term high-dose opioids for chronic pain

31. Knisely JS, Wunsch MJ, Cropsey KL et al. Prescription Opioid Misuse Index: a brief questionnaire to assess misuse. Journal of substance abuse treatment 2008; 35: 380-386.

32. Moore TM, Jones T, Browder JH et al. A comparison of common screening methods for predicting aberrant drug-related behavior among patients receiving opioids for chronic pain management. Pain Medicine 2009; 10: 1426-1433.

33. Boscarino JA, Rukstalis M, Hoffman SN et al. Risk factors for drug dependence among outpatients on opioid therapy in a large US health-care system. Addiction 2010; 105: 1776-1782.

34. Liebschutz JM, Saitz R, Weiss RD et al. Clinical factors associated with prescription drug use disorder in urban primary care patients with chronic pain. Journal of Pain 2010; 11: 1047-1055.

35. Pink LR, Smith AJ, Peng PW et al. Intake assessment of problematic use of medications in a chronic noncancer pain clinic. Pain Research \& Management 2012; 17: 276-280.

36. Morasco BJ, Turk DC, Donovan DM et al. Risk for prescription opioid misuse among patients with a history of substance use disorder. Drug and alcoholdependence 2013; 127: 193-199.

37. Higgins $\mathrm{C}$, Smith BH and Matthews $\mathrm{K}$ Incidence of iatrogenic opioid dependence or abuse in patients with pain who were exposed to opioid analgesic therapy: a systematic review and meta-analysis. British Journal of Anaesthesia, 2018; 120: 1335-1344.

38. Martel MO, Shir Y and Ware MA Substance-related disorders: A review of prevalence and correlates among patients with chronic pain. Progress in neuro-psychopharmacology \& biological psychiatry, 2018; 87 245-254.

39. Sehgal N, Manchikanti L and Smith, HS. Prescription opioid abuse in chronic pain: a review of opioid abuse predictors and strategies to curb opioid abuse. Pain Physician 2012; 15(3Sup): ES67-92.

40. Kaye $A D$, Jones $M R$, Kaye $A M$ et al. Prescription Opioid Abuse in Chronic Pain: An Updated Review of Opioid Abuse Predictors and Strategies to Curb Opioid Abuse: Part 1. Pain Physician 2017; 20: S93-S109.

41. Bailey RW and Vowles KE. Using screening tests to predict aberrant use of opioids in chronic pain patients: Caveat emptor. Journal of Pain, 2017; 18: 1427-1436.

42. Chalmers CE, Mullinax S, Brennan J et al. Screening tools validated in the outpatient pain management setting poorly predict opioid misuse in the emergency department: a pilot study. Journal of Emergency Medicine, 2019; 56: 601-610.

43. Schofferman J. Long-term use of opioid analgesics for the treatment of chronic pain of nonmalignant origin. Journal of Pain and Symptom Management 1993 8: 279-288.

44. Chu LF, Angst MS and Clark D. Opioid-induced hyperalgesia in humans: molecular mechanisms and clinical considerations. Clinical journalof pain 2008; 24: 479-496. 
Rationalisation of long-term high-dose opioids for chronic pain

45. Silverman MD. Opioid induced hyperalgesia: Clinical implications for the pain practitioner. Pain Physician 2009; 12: 679-684.

46. Varrassi G, Fusco M, Skaper SD et al. A pharmacological rationale to reduce the incidence of opioid induced tolerance and hyperalgesia: A review. Pain and Therapy 2018; 7: 59-75.

47. Chou R, Ballantyne JC, Fanciullo GJ et al. Research gaps on use of opioids for chronic noncancer pain: Findings from a review of the evidence for an American Pain Society and American Academy of Pain Medicine Clinical Practice Guideline. Journal of Pain 2009; 10: 147-159.

48. Manchikanti L, Benyamin R Datta S et al. Opioids in chronic non-cancerpain. Expert Review of Neurotherapeutics 2010; 10: 775-789.

49. Eccleston $\mathrm{C}$, Fisher $\mathrm{E}$, Thomas $\mathrm{KH}$ et al. Interventions for the reduction of prescribed opioid use in chronic non-cancer pain. Cochrane Database of Systematic Reviews 2017; Issue 11. Art. No.: CD010323.

50. Frank JW, Lovejoy TI, Becker WC et al. Patient outcomes in dose reduction or discontinuation of long-term opioid therapy: A systematic review. Annals of InternalMedicine 2017; 167: 181-191.

51. Chou R, Fanciullo GJ, Fine PG et al. Clinical guidelines for the use of chronic opioid therapy in chronic noncancer pain. Journal of Pain 2009; 10: 113-130.

52. Manchikanti, L; AbdiS, Atluri S et al. American Society of Interventional Pain Physicians (ASIPP) guidelines for responsible opioid prescribing in chronic non-cancer pain: Part 2--guidance. Pain Physician 2012; 15(3Sup); 67-116.

53. Berna C, Kulich RJ and Rathmell JP. Tapering long-term opioid therapy in chronic non-cancer pain: evidence and recommendations for everyday practice. Mayo Clinic Proceedings 2015; 90: 828-842.

54. Dowell D, Haegerich M and Chou R. CDC guideline for prescribing opioids for chronic pain United States, 2016. Journal of the American Medical Association 2016; 315: 1624-1645.

55. RCoA, Faculty of Pain Medicine. Opioids Aware: Tapering and stopping.

https://www.rcoa.ac.uk/faculty-of-pain-medicine/opioids-aware/structured-approach-toprescribing/tapering-and-stopping. (2020, accessed 28 February 2020).

56. Sullivan MD, Turner JA, DiLodovico $C$ et al. Prescription opioid taper support for outpatients with chronic pain: A randomized controlled trial. Journal of Pain 2017; 18: 308-318.

57. Kurita GP, Højsted J and Sjøgren P. Tapering off long-term opioid therapy in chronic non-cancer pain patients: A randomized clinical trial. European Journal of Pain 2018; 22: 1528-1543.

58. Manhapra A, Arias AA and Ballantyne JC The conundrum of opioid tapering in long-term opioid therapy for chronic pain: A commentary. Substance Abuse 2018; 39(2): 152-161.

59. Clinical Guidelines on Drug Misuse and Dependence Update 2017 Independent Expert Working Group (2017) Drug misuse and dependence: UK guidelines on clinical management. London: Department of Health 
Rationalisation of long-term high-dose opioids for chronic pain

60. Maxwell, S. Rational prescribing: the principles of drug selection. Clinical Medicine 2009; 9: 481485.

61. Selvini Palazzoli M, Boscolo L, Cecchin G and Prata G. Hypothesizing-Circularity-Neutrality: Three guidelines for the conductor of the session. Family Process 1980; 19, 3-12.

62. Brown JM. (2010). The Milan principles of hypothesizing, circularity and neutrality in dialogical family therapy: extinction, evolution, eviction... or emergence? Australian and New Zealand Journal of Family Therapy 2010; 31(3), 248-65.

63. Cleeland CS and Ryan KM. Pain assessment: Global use of the Brief Pain Inventory. Annals, Academy of Medicine, Singapore 1994; 23: 129-138.

64. Zigmond AS and Snaith, RP. The hospital anxiety and depression scale. Acta Psychiatrica Scandinavica 1983; 67: 361-370.

65. PROMIS. Ability to Participate in Social Roles and Activities - Calibrated Items http://www. healthmeasures.net/administrator/components/com instruments/uploads/15-0901_15-37-40_PROMISBankv2.0-AbilityParticinSocRolesandActivities.pdf. (2014, accessed 12 August 2019).

66. RCoA, Faculty of Pain Medicine. Dose equivalents and changing opioids. https://fpm.ac.uk/opioids-aware-structured-approach-opioid-prescribing/dose-equivalents-andchanging-opioids. (2020, accessed 28 February 2020). 


\title{
Supplement 1
}

Pain Management Team

\author{
GPInformation Sheet
}

\section{Complex Medication Clinic:}

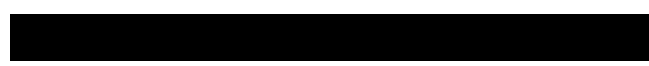

March 2019

The medical management of long term painful conditions is complex, and this clinic exists in order to maximise patient's quality of life. For many patients with chronic non-cancer pain, the outcome of treatment is disappointing. They often have poor symptom relief despite high doses of opio id and adjunctive medications, and there is a high burden of side-effects.

This poor outcome is in part due to opioid-induced hyperalgesia, which can trap patient and prescriber alike in a cycle of increasing doses, with initial improvement in symptoms that is not sustained over time.

Although some patients on high doses of opioids and GABA drugs have characteristics suggestive of addiction, this clinic does not primarily caterfor that group. We do, however, sometimes make referrals to Substance Misuse Services where this is appropriate.

The rationale underlying our programme is that withdrawal of unhelpful medications and reductions in dosage can lead to better pain management through reduced cognitive and mood side effects, alongside teaching patients to manage their pain. This is a more realistic approach than perpetuating an unattainable target of pain elimination through medication.

The clinic is part of the Pain Management Team service, and is conducted by nurse specialist in pain management, and senior Consultant Psychiatrist.

In the clinic, we reassess people's pain and personal histories. In the case of adjunctive medications, withdrawal and/or discontinuation is achieved through a supervised graded reduction. In the case of opioids, we sometimes conducted graded reduction. However, this is problematic, as hyperalgesia means that pain increases on dose reduction before attenuating to the previous level. Graded reduction can be a slow and demoralising process before gains are finally seen. It can also feed into patients' fears that their condition is especially severe, requiring massive doses of medication, without which they will overwhelmed by pain.

Consequently, and for selected patients, we offer rapid dose reduction from high dose opioids (in excess of oral morphine equivalent dose $120 \mathrm{mg}$ per day) to a low dose, fixed regime of methadone $10 \mathrm{mg}$ bd (adjusted to an absolute maximum of $20 \mathrm{mg} \mathrm{bd}$ ). Methadone is selected because of its 
pharmacokinetic and other properties, not because we believe the patient to be a 'drug addict'. The patient is given a card or letter indicating this.

This change is effected overnight, with a very high level of preparation and support from the clinic for the patient and their family. We do not carry out this process unless the patient fully consents. We offer the treatment objective of pain that is no worse than on the previous regime, but with significantly less side effects. Most patients experience improved pain relief.

If patients wish to return to their previous regime (e.g. Fentanyl), we will organise this, albeit at a dose appropriate to their current level of opioid tolerance. In our experience, even those patients who do this only ever return to a lower dose of opioids than at the start.

We do not institute this regime if the patient's GP raises a medical contra-indication. If you feel that there is such a contra-indication, please contact the pain team secretary

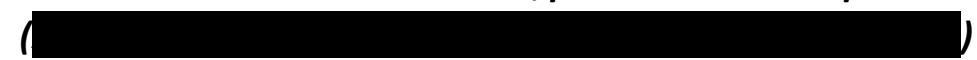

\section{Management of patients during and after change of opioid regime}

The change is only made when the patient's family is available to support them, and when [senior nurse specialist] and [consultant psychiatrist] are available to offer telephone/face to face support to all concerned, including the GP.

Methadone is prescribed by [consultant psychiatrist] from the hospital pharmacy. It is essential that no other opioids are prescribed for the duration of methadone treatment and that control of long term pain medication is retained by the clinic. In the event of an unexpected medical complication or trauma that requires opioid analgesia, methadone should immediately be discontinued and the patient treated as if opioid niave. [Consultant psychiatrist] or [senior nurse specialist] must be informed on [telephone and email] in order to discontinue supply of methadone. They will give advice if this is required.

Patients are instructed to discontinue their standard opioid medication after their last dose on a specific Sunday. In the case of patches, the patch is usually removed on the Saturday night. On Monday morning, they commence on Methadone $10 \mathrm{mg}$ bd, and there is a telephone review by [senior nurse specialist] on Tuesday. On Thursday, patient and family are seen in clinic, and continue with twice weekly contact until symptoms have stabilised. Patients normally feel substantially improved within 4-5 days. About half of patients experience significant withdrawal symptoms, which can be controlled to some extent with PRN loperamide whilst diarrhoea and cramps continue. There is transient restlessness and sleep disturbance in many cases, and pain may worsen before improving again.

Patients are followed up for as long as is necessary and will not be discharged to GP unless an agreement is made with an individual GP for continuing treatment and monitoring. 